University of Nebraska - Lincoln

DigitalCommons@University of Nebraska - Lincoln

Contributions of the maternal uterine environment and piglet genotype on weaning survivability potential: I. Development of neonatal piglets after reciprocal embryo transfers between Meishan and White crossbred gilts

Jeremy R. Miles

USDA-ARS, jeremy.miles@usda.gov

J. L. Vallet

USDA-ARS, Jeff.Vallet@ars.usda.gov

J. J. Ford

USDA-ARS

Brad A. Freking

USDA-ARS, brad.freking@ars.usda.gov

R. A. Cushman

USDA-ARS, Bob.Cushman@ars.usda.gov

See nextpage for additional authors Foltow this and additional works at: httpsitalcommons.unl.edu/hruskareports

Miles, Jeremy R.; Vallet, J. L.; Ford, J. J.; Freking, Brad A.; Cushman, R. A.; Oliver, William T.; and Rempel, Lea Ann, "Contributions of the maternal uterine environment and piglet genotype on weaning survivability potential: I. Development of neonatal piglets after reciprocal embryo transfers between Meishan and White crossbred gilts" (2012). Roman L. Hruska U.S. Meat Animal Research Center. 268.

https://digitalcommons.unl.edu/hruskareports/268

This Article is brought to you for free and open access by the U.S. Department of Agriculture: Agricultural Research Service, Lincoln, Nebraska at DigitalCommons@University of Nebraska - Lincoln. It has been accepted for inclusion in Roman L. Hruska U.S. Meat Animal Research Center by an authorized administrator of DigitalCommons@University of Nebraska - Lincoln. 


\section{Authors}

Jeremy R. Miles, J. L. Vallet, J. J. Ford, Brad A. Freking, R. A. Cushman, William T. Oliver, and Lea Ann Rempel 


\title{
Contributions of the maternal uterine environment and piglet genotype on weaning survivability potential: I. Development of neonatal piglets after reciprocal embryo transfers between Meishan and White crossbred gilts ${ }^{1,2}$
}

\author{
J. R. Miles, ${ }^{3}$ J. L. Vallet, J. J. Ford, B. A. Freking, R. A. Cushman, W. T. Oliver, and L. A. Rempel \\ USDA4-ARS, U.S. Meat Animal Research Center, Clay Center, NE 68933
}

\begin{abstract}
In commercial pigs, the greatest susceptibility for pre-weaning mortality occurs in low birth-weight piglets. Despite their overall decreased birth weight, Meishan (MS) piglets have decreased preweaning mortality rates compared with contemporary Western breeds. The objective of the current study was to determine the contributions of the maternal uterine environment, piglet genotype, and their interaction on the development of neonatal piglets pertaining to preweaning survivability using reciprocal embryo transfer between MS and White crossbred (WC) pigs. Twentyfive successful pregnancies were produced from 2 farrowing seasons, generating litters of maternal uterine environment (MUE) by piglet genotype (PigG) combinations; $\mathrm{MS} \times \mathrm{MS}(\mathrm{n}=4$ litters $), \mathrm{MS} \times \mathrm{WC}(\mathrm{n}=7$ litters), WC $\times$ MS ( $n=7$ litters $)$, and $\mathrm{WC} \times \mathrm{WC}(\mathrm{n}=$ 7 litters). At approximately $24 \mathrm{~h}$ of age (Day 1), piglets $(n=173)$ were weighed and a blood sample was taken. Hematocrit, hemoglobin, glucose, plasma urea nitrogen, albumin, NEFA, lactate, and cortisol were measured in all blood samples. Representative piglets $(n=46)$ from each litter were harvested and body measurements (i.e., organ weights, tissue glycogen content, and body composition) were determined. Piglet data were analyzed by
\end{abstract}

ANOVA using MIXED model procedures. Both MUE $(P<0.001)$ and PigG $(P<0.01)$ affected piglet BW, illustrating that piglets gestated in $\mathrm{WC}$ gilts were heavier than piglets gestated in MS gilts, and WC piglets were heavier than MS piglets. Serum albumin concentrations were increased $(P<0.05)$ in MS piglets compared with WC piglets, indicating greater liver maturity. Significant MUE $\times$ PigG interactions were observed for hematocrit and hemoglobin, in which the greatest concentrations were observed in MS piglets gestated in MS and WC gilts, and the lowest concentrations were observed in WC piglets gestated in WC gilts, demonstrating increased oxygen-carrying capability. The percentage of fat and nitrogen, as well as the GE of the body, were greater $(P$ $<0.05)$ in MS piglets, indicating greater energy stores. Liver, bicep femoris, and LM glycogen concentrations were greater $(P<0.01)$ in WC piglets compared with MS piglets, demonstrating increased glycogen catabolism in MS piglets. This study demonstrated limited interactions between the maternal uterine environment and piglet genotype on weaning survivability potential, suggesting that the MS piglet is a viable model for pre-weaning survivability.

Key words: embryo transfer, energy store, glycogen, Meishan pig, pre-weaning mortality, White crossbred pig

(C) 2012 American Society of Animal Science. All rights reserved.

This article is a U.S. government work, and is not subject to copyright in the United States.
J. Anim. Sci. 2012.90:2181-2192

doi:10.2527/jas2011-4724

\footnotetext{
${ }^{1}$ Mention of trade names is necessary to report factually on available data; however, the USDA neither guarantees nor warrants the standard of the product, and the same by USDA implies no approval of the product to the exclusion of others that may also be suitable.

${ }^{2}$ The authors thank Susan Hassler, Troy Gramke, and Jeff Waechter for technical assistance in collection and processing of samples and data collection, Linda Parnell for secretarial assistance, the USMARC swine crew for animal husbandry, Steven Ford and
}

Ronald Christenson for advice on embryo transfer protocols, Tara McDaneld, Gail Miles, and Matthew Wilson for critical review of this manuscript. Research supported by USDA-ARS, CRIS Project No. 5438-31000-084.

${ }^{3}$ Corresponding author: Jeremy.Miles@ars.usda.gov

${ }^{4}$ The USDA is an equal opportunity provider and employer. Received September 19, 2011.

Accepted January 6, 2012. 


\section{INTRODUCTION}

Sow productivity is a key component influencing the profitability of the swine industry. Pre-weaning piglet mortality plays a major role in sow productivity and affects $13 \%$ of all live-born piglets in the United States (PigCHAMP, 2010). In contemporary Western breeds, low birth-weight piglets exhibit the greatest susceptibility to pre-weaning mortality (Tuchscherer et al., 2000; Damgaard et al., 2003). However, Meisham (MS) piglets have reduced pre-weaning mortality rates (Legault, 1985; Lee and Haley, 1995), despite their lighter birth weights compared with Western breeds. Previous studies comparing body composition and blood components of newborn MS and Western breed piglets suggest that MS piglets have greater physiological maturity immediately after parturition, which benefits early neonatal survival (Stone et al., 1985; Le Dividich et al., 1991; Herpin et al., 1993). Crossbreeding studies between MS and Large White (LW) pigs have illustrated that prenatal survival is primarily attributed to a maternal genotypic effect in favor of MS dams (Haley et al., 1995). In contrast, postnatal survival is primarily attributed to a direct genotypic effect in favor of MS piglets (Lee and Haley, 1995). Piglet birth weight was attributed to a maternal genotypic effect in favor of LW dams (Lee and Haley, 1995). Reciprocal embryo transfer studies between MS and Yorkshire pigs illustrated interactions between maternal environment and direct fetal genotype on fetal and placental growth during late gestation, which may be driven by difference in placental vasculature between these breeds (Biensen et al., 1998; Wilson et al., 1998). The objective of the current study was to determine the contributions of the maternal uterine environment, the piglet genotype, and their interaction on the development of neonatal piglets pertaining to pre-weaning survivability using reciprocal embryo transfer between MS and White crossbred (WC) pigs.

\section{MATERIALS AND METHODS}

All animal protocols were approved by the United States Meat Animal Research Center (USMARC) Animal Care and Use Committee and met the USDA guidelines for the care and use of animals.

\section{Animals}

Purebred Chinese MS were imported to the USMARC from China in 1989 and have been maintained by inter se matings among 8 sire lines. Composite WC pigs were produced by mating a founder Yorkshire-Landrace (YL) composite population generated at the USMARC to commercially available semen from unrelated Duroc or high-lean Landrace boars. The second generation were then reciprocally bred to create a 4-line composite WC line that has been maintained by inter se matings among 10 sire lines (Holl et al., 2008). All pigs were fed with a corn (Zea mays L.) — soybean [Glycine max (L.) Merr.] meal diet formulated to meet or exceed NRC recommendations (NRC, 1998). These diets ranged in protein content depending upon stage of growth and development (growing diet $=16 \%$ protein; breeding diet $=12.5 \%$ protein; gestation and lactation $=16.9 \%$ protein) .

\section{Embryo Transfer Protocols}

Embryo transfers were performed consecutively in the January 2007 and 2008 farrowing seasons at the USMARC. Within each farrowing season, equal numbers of MS and WC gilts ( $\mathrm{n}=48$ and 48, respectively) observed having at least 1 previous estrous cycle were synchronized using $15 \mathrm{mg}$ altrenogest (Matrix; Intervet/ Schering-Plough, Millsboro, DE) once daily added to feed for $14 \mathrm{~d}$. Estrus was induced after an intramuscular (IM) injection of 750 IU hCG (Chorulon; Intervet/ Schering-Plough) on $\mathrm{d} 5$ after the last dose of altrenogest. One-half of the gilts $(n=48)$ were assigned randomly as embryo donors and mated to boars within their respective breed ( 8 and 10 sire lines were used for breeding MS and WC gilts, respectively) $24 \mathrm{~h}$ after hCG (d 0 ) and again $24 \mathrm{~h}$ later. The remaining gilts were used as embryo recipients and were checked for estrus daily to ensure proper synchrony with the donors. Embryos were recovered from both donor oviducts via mid-ventral laparotomy approximately 48 to $54 \mathrm{~h}$ post initial breeding after a surgical embryo transfer protocol as previously described (Youngs et al., 1994). Briefly, donor and recipient gilts were sedated with acepromazine $(0.3 \mathrm{mg} / \mathrm{kg}$ BW; IM; Iowa Veterinary Supply Company, Sioux City, IA) followed by induction of anesthesia using thiopental sodium $(9.6 \mathrm{mg} / \mathrm{kg} \mathrm{BW}$; IM; Iowa Veterinary Supply Company) and maintained using isoflurane (Iowa Veterinary Supply Company). For embryo recovery, the uterus of each donor was exteriorized and cannulated with a siliconized (Sigmacote; Sigma-Aldrich, St. Louis, MO) glass cannula via an incision made $10 \mathrm{~cm}$ from the utero-tubal junction on each uterine horn. Embryos were recovered by flushing each oviduct with $20 \mathrm{~mL}$ of warm $\left(35^{\circ} \mathrm{C}\right)$ media [Dulbecco's PBS supplemented with $2 \%$ fetal bovine serum (Invitrogen, Carlsbad, CA) and $1 \%$ antibiotic/antimycotic (Invitrogen)]. Embryos were transferred to fresh media and evaluated for evidence of fertilization, as measured by cleavage, and blastomere numbers. The numbers of corpora hemorrhagica were determined from each ovary to assess ovulation and embryo recovery rates. For embryo transfer, a single oviduct from a synchronized recipient was 
minimally exteriorized via mid-ventral laparotomy to expose 1 ovary. This minimal exteriorization was used to limit adhesions. Corpora hemorrhagica were noted to ensure ovulation had recently occurred in recipients before transfer. All embryos collected from a single donor were transferred in $10 \mu \mathrm{L}$ of fresh media using a tom-cat catheter (Reproduction Resources, Walworth, WI) that was threaded through a blunt, 12-gauge needle inserted in the fimbria end of the exteriorized oviduct. Resulting embryo transfers produced maternal uterine environment (MUE) by piglet genotype (PigG) combinations (i.e., $\mathrm{MS} \times \mathrm{MS}$; $\mathrm{MS} \times \mathrm{WC}$; $\mathrm{WC} \times \mathrm{MS}$; and $\mathrm{WC} \times \mathrm{WC}$ ).

\section{Embryo Donor and Recipient Data}

Data collected for embryo donors included age at embryo transfer, ovulation rate, pregnancy rate, total recovery (i.e., oocytes and embryos), embryo recovery, and fertilization rate. Fertilization rate for donors was only assessed on total recovery of oocytes and embryos. Data for embryo recipients included age at embryo transfer, number of embryos transferred, and farrowing rate. Recipient gilts that maintained pregnancy were transferred to a farrowing barn at Day 110 of gestation and farrowed in crates. Approximately $24 \mathrm{~h}$ after parturition, the litters were processed using normal management procedures (i.e., piglets were weighed, sex determined, tails docked, and ears notched), and stillborn and mummified piglets were identified and recorded. Total litter size was based on recovery of all live and dead piglets. Additional data for recipient gilts included number born alive (NBA), preand peri-natal survival, gestation length, and average piglet BW. Prenatal survival included live and stillborn piglets recovered, whereas perinatal survival only included live-born piglets to the ratio of total embryos transferred.

\section{Piglet Data}

During litter processing (Day 1), all live piglets blood samples $(5 \mathrm{~mL})$ were collected via jugular venipuncture using heparinized syringes. Blood was analyzed for hemoglobin within $1 \mathrm{~h}$ of collection using a Hemoximeter, model OSM-2 (Radiometer America, Westlake, $\mathrm{OH}$ ) and hematocrits were determined using standard hematocrit tubes and centrifugation. After measuring hemoglobin and hematocrit, blood was centrifuged at $2000 \times \mathrm{g}$ for $10 \mathrm{~min}$ at $4^{\circ} \mathrm{C}$ and plasma was stored at $-20^{\circ} \mathrm{C}$. Plasma glucose, urea nitrogen (PUN), and albumin were analyzed using the Technicon Autoanalyzer (Technicon Industrial Systems, Tarrytown, NY). For glucose, PUN, and albumin, samples were assayed in duplicate with intra-assay $\mathrm{CV}$ of $0.5,0.6$, and $3.2 \%$, respectively. Plasma NEFA concentrations were measured in duplicate using an enzymatic colorimetric method (Wako Pure Chemical Industries, Richmond, VA) with intra-assay CV of 5.4\%. Plasma lactate was determined using an immobilized enzyme system (model 2700 YSI, Yellow Springs Instruments, Yellow Springs, $\mathrm{OH})$. Cortisol was measured using a commercial RIA kit (Diagnostic Systems Laboratories, Webster, TX) previously described and validated in swine (Wise et al., 2000). For cortisol concentrations, samples were measured in duplicate in 3 assays with an intra-assay and inter-assay CV of 9.7 and $12.6 \%$, respectively.

Immediately after processing, representative piglets from each litter were identified and selected based on BW (i.e., heaviest, average, and lightest) to be euthanized and processed for body measurements (i.e., organ weights, tissue glycogen content, and body composition). The selection of piglets was based on litter size [i.e., small litters ( $\leq 3$ piglets), only the lightest piglet was selected; medium litters (4-6 piglets), the lightest and heaviest piglets were selected; and large litters ( $\geq 7$ piglets) the lightest, average, and heaviest piglets were selected]. These selections were made to ensure adequate surviving piglets from each litter could be used for follow-up studies. The selected piglets were euthanized with exposure to $\mathrm{CO}_{2}$ gas followed by immediate exsanguination. After euthanasia, the eviscerated body and total viscera were weighed and the gastrointestinal (GI) tract content was removed and weighed. Organ weights (i.e., heart, lungs, liver, spleen, kidneys, and empty GI tract) were determined. A sample of liver, as well as bicep femoris and LM from the right side of the carcass, were collected and stored at $-80^{\circ} \mathrm{C}$ for later assessment of glycogen concentration. Glycogen concentrations were determined using a previously described method that used 5\% trichloroacetic acid extraction, 95\% ethanol precipitation, and a colorimetric detection method with anthrone reagent (Carroll et al., 1956). The entire viscera and intact left side of the carcass with the head and spinal cord were frozen at $-20^{\circ} \mathrm{C}$. After freezing, the viscera and carcass were ground to a consistent homogenate using a commercial meat grinder (Hobart Corp., Troy, OH). Homogenates were used to determine body composition analysis (i.e., DM, moisture, fat, nitrogen, ash, and GE) using standard proximate analysis (AOAC, 1997).

\section{Statistical Analysis}

All data were analyzed using either GLM, GLIMMIX, or MIXED model procedures for ANOVA (Steel et al., 1997; SAS Inst., Cary, NC), and results are reported as least squares means \pm SEM. When a significant $F$-statistic was generated, means were separated using a Dunnett multiple comparison test (Steel et al., 1997; SAS Inst., Cary, NC). When multiple fixed effects had a significant $F$-statistic, the solution for fixed effects 
was used to determine the contribution of the significant fixed effects. Means were considered statistically different at $P \leq 0.05$ and tendencies between $P=0.06$ and $P=0.10$. Donor age, recipient age, and the number of donor corpora hemorrhagica were analyzed using GLM procedures for ANOVA with a model including the fixed effects of breed, farrowing year, and the interactions of fixed effects. Embryo recovery (i.e., pregnancy rate, embryo recovery rate, and fertilization rate) and recipient transfer data (i.e., embryo transferred, farrowing rate, and pre- and peri-natal survival) were analyzed using GLIMMIX procedures for ANOVA with a model including the fixed effects donor or recipient breed, farrowing year, the interactions of fixed effects, and the random effect of boar within year $\times$ donor or recipient breed interaction. Average litter data (i.e., litter size, NBA, gestation length, and litter average piglet BW) were analyzed using MIXED procedures for ANOVA with a model including the fixed effect of MUE, PigG, farrowing year, the interactions of fixed effects, and the random effect of boar within year $\times$ MUE $\times$ PigG interaction. The model for gestation length and litter average piglet $\mathrm{BW}$ also included the covariate of litter size.

Individual piglet BW was analyzed using MIXED procedures for ANOVA with a model including the fixed effect of MUE, PigG, farrowing year, piglet sex, the interactions of fixed effects, the covariate of litter size, and the random effect of recipient gilt within farrowing year $\times$ MUE $\times$ PigG interaction. All other piglet variables (i.e., blood and plasma components, organ weights, tissue glycogen concentrations, and body composition) were analyzed using MIXED procedures for ANOVA with a model including the fixed effect of MUE, PigG, farrowing year, piglet sex, the interactions of fixed effects, the covariates of litter size and piglet BW, and the random effect of sow within farrowing year $\times$ MUE $\times$ PigG interaction. Before analyzing tissue glycogen concentrations, glycogen data were log transformed to normalize for statistical analysis and back transformed to the measured scale for presentation.

\section{RESULTS}

\section{Embryo Recovery and Embryo Transfer}

A total of 79 embryo donors were flushed in 2 sequential farrowing years (Table 1). The MS donors were older $(P \leq 0.001)$ in the 2007 farrowing year compared with WC donors in both 2007 and 2008; however, MS donors were younger in the 2008 farrowing year. The discrepancy in the age of MS gilts was the result of a management

Table 1. Recovery data from Meishan (MS) and White Crossbred (WC) gilts used as embryo donors for generating intrabreed- and reciprocal-embryo transfer pregnancies ${ }^{1}$

\begin{tabular}{|c|c|c|c|c|c|}
\hline Variable & \multicolumn{2}{|c|}{ Fixed effect } & \multicolumn{2}{|c|}{ Fixed effect } & $P$-value \\
\hline & \multicolumn{2}{|c|}{$\mathrm{MS}^{2}(\mathrm{n}=40)$} & \multicolumn{2}{|c|}{$\mathrm{WC}(\mathrm{n}=39)$} & \\
\hline Age, d & \multicolumn{2}{|c|}{$222.3 \pm 1.2$} & \multicolumn{2}{|c|}{$250.5 \pm 1.2$} & $<0.001$ \\
\hline Corpora hemorrhagica, $\mathrm{n}$ & \multicolumn{2}{|c|}{$17.1 \pm 0.5$} & \multicolumn{2}{|c|}{$16.1 \pm 0.5$} & 0.13 \\
\hline Pregnant, \% & \multicolumn{2}{|c|}{$92.9 \pm 4.4$} & \multicolumn{2}{|c|}{$94.8 \pm 3.8$} & 0.75 \\
\hline Oocyte and embryo recovery, $\%$ & \multicolumn{2}{|c|}{$82.2 \pm 2.1^{\mathrm{a}}$} & \multicolumn{2}{|c|}{$91.1 \pm 2.1^{b}$} & 0.006 \\
\hline Fertilized embryo recovery, \% & \multicolumn{2}{|c|}{$74.4 \pm 3.3^{\mathrm{a}}$} & \multicolumn{2}{|c|}{$84.6 \pm 3.3^{b}$} & 0.04 \\
\hline \multirow[t]{2}{*}{ Fertilization, $\%$} & \multicolumn{2}{|c|}{$91.5 \pm 3.0$} & \multicolumn{2}{|c|}{$92.5 \pm 3.0$} & 0.81 \\
\hline & \multicolumn{2}{|c|}{$2007^{3}(n=44)$} & \multicolumn{2}{|c|}{$2008(n=36)$} & \\
\hline Age, d & \multicolumn{2}{|c|}{$253.9 \pm 1.1$} & \multicolumn{2}{|c|}{$219.2 \pm 1.2$} & $<0.001$ \\
\hline Corpora hemorrhagica, $n$ & \multicolumn{2}{|c|}{$18.0 \pm 0.4$} & \multicolumn{2}{|c|}{$15.1 \pm 0.5$} & $<0.001$ \\
\hline Pregnant, \% & \multicolumn{2}{|c|}{$93.4 \pm 4.1$} & \multicolumn{2}{|c|}{$94.3 \pm 4.1$} & 0.88 \\
\hline Oocyte and embryo recovery, $\%$ & \multicolumn{2}{|c|}{$86.3 \pm 2.1$} & \multicolumn{2}{|c|}{$91.1 \pm 2.2$} & 0.82 \\
\hline Fertilized embryo recovery, \% & \multicolumn{2}{|c|}{$79.5 \pm 3.1$} & \multicolumn{2}{|c|}{$79.8 \pm 3.4$} & 0.94 \\
\hline \multirow[t]{3}{*}{ Fertilization, $\%$} & \multicolumn{2}{|c|}{$91.9 \pm 2.9$} & \multicolumn{2}{|c|}{$92.0 \pm 3.1$} & 0.98 \\
\hline & $\longrightarrow$ & - & $\longrightarrow$ & - & \\
\hline & $2007^{3}(\mathrm{n}=21)$ & $2008(n=19)$ & $2007(\mathrm{n}=22)$ & $2008(n=17)$ & $2007^{3}(\mathrm{n}=21)$ \\
\hline Age, d & $258.9 \pm 1.6^{\mathrm{a}}$ & $185.8 \pm 1.7^{\mathrm{b}}$ & $249.0 \pm 1.6^{c}$ & $252.7 \pm 1.8^{\mathrm{c}}$ & $<0.001$ \\
\hline Corpora hemorrhagica, $n$ & $19.6 \pm 0.6^{\mathrm{a}}$ & $14.6 \pm 0.7^{\mathrm{b}}$ & $16.4 \pm 0.6^{\mathrm{b}}$ & $15.7 \pm 0.7^{b}$ & 0.002 \\
\hline Pregnant, \% & $90.6 \pm 6.9$ & $94.7 \pm 5.4$ & $95.4 \pm 4.6$ & $94.0 \pm 6.1$ & 0.66 \\
\hline Oocyte \& embryo recovery, $\%$ & $81.7 \pm 2.7$ & $83.3 \pm 2.8$ & $90.7 \pm 2.6$ & $91.3 \pm 3.0$ & 0.87 \\
\hline Fertilized embryo recovery, \% & $73.3 \pm 4.5$ & $76.2 \pm 5.7$ & $85.7 \pm 4.3$ & $83.4 \pm 4.8$ & 0.57 \\
\hline Fertilization, $\%$ & $89.9 \pm 4.1$ & $93.0 \pm 4.2$ & $93.9 \pm 4.0$ & $91.0 \pm 4.4$ & 0.48 \\
\hline
\end{tabular}


change in which MS were moved to a later farrowing season after 2007. As a result, MS donors in 2007 had a greater $(P \leq 0.01)$ ovulation rate compared with younger MS donors in 2008, and WC donors in 2007 and 2008. There were no breed, year, or breed $\times$ year interactions for the percentage of donors that were pregnant, or the fertilization rate based on recovered embryos. Interestingly, total oocyte and embryo recovery and, subsequently, embryo recovery were reduced $(P \leq 0.05)$ in MS donors compared with WC donors. A total of 74 embryo recipients were used for embryo transfers (Table 2). Again, similar to the donors, MS recipients in the 2007 farrowing year were older $(P \leq 0.001)$ compared with WC recipients in 2007 and 2008; however, MS recipients in the 2008 farrowing year were younger. In 2007, recipients received more $(P \leq 0.05)$ embryos compared with 2008 ; however, there were no breed, year, or breed $\times$ year interactions for litter size or farrowing rate.

\section{Pregnancy Outcome and Litter Variables}

A total of 25 successful pregnancies were produced after intrabreed- and reciprocal-embryo transfer between MS and WC gilts (Table 3$)$. There were no effects $(P \geq$ 0.10 ) of year, MUE $\times$ year, $\mathrm{PigG} \times$ year, or MUE $\times$ PigG $\times$ year interactions for the litter variables (i.e., farrowing rate, pre- and peri-natal survival, litter size, NBA, gestation length, and average piglet BW; data not shown). A significant MUE $\times$ PigG interaction was detected for far- rowing rate in which the reciprocal transfer groups (i.e., $\mathrm{MS} \times \mathrm{WC}$ and $\mathrm{WC} \times \mathrm{MS})$ had reduced $(P \leq 0.05)$ farrowing rates compared with the intrabreed transfer groups. However, there was no significant effect of MUE, PigG, or MUE $\times$ PigG interaction for pre- and peri-survival or litter size and NBA. It is important to highlight that litter size and particularly prenatal survival were numerically decreased in MS piglets, irrespective of MUE. In contrast, gestation length was greater $(P \leq 0.001)$ in WC piglets compared with MS piglets, irrespective of MUE. Both MUE and PigG significantly affected litter average piglet BW. Piglets gestated in WC recipient gilts were heavier $(P \leq 0.01)$ than piglets gestated in MS recipient gilts, and WC piglets were heavier $(P \leq 0.05)$ than MS piglets. Analysis of the solution for fixed effects of litter average piglet BW illustrated that MUE accounted for $61 \%$ of the variation compared with $39 \%$ for PigG.

\section{Individual Piglet Body Weight and Blood Component Profiles}

Table 4 illustrates the individual piglet BW and piglet blood component profiles (corrected for BW) at Day 1 of age. There were no significant effects of MUE, PigG, and MUE $\times$ PigG interaction for plasma NEFA, lactate, and cortisol. Similar to litter average piglet BW, both MUE and PigG significantly affected individual piglet BW. Piglets gestated in WC recipient gilts were larger $(P \leq 0.01)$ than piglets gestated in MS recipient

Table 2. Transfer data from Meishan (MS) and White Crossbred (WC) gilts used as embryo recipients to generate intrabreed- and reciprocal-embryo transfer pregnancies ${ }^{1}$

\begin{tabular}{|c|c|c|c|c|c|}
\hline Variable & \multicolumn{2}{|c|}{ Fixed effect } & \multicolumn{2}{|c|}{ Fixed effect } & $P$-value \\
\hline & \multicolumn{2}{|c|}{$\mathrm{MS}^{2}(\mathrm{n}=30)$} & \multicolumn{2}{|c|}{$\mathrm{WC}(\mathrm{n}=44)$} & \\
\hline Age, $d$ & \multicolumn{2}{|c|}{$223.7 \pm 1.2$} & \multicolumn{2}{|c|}{$250.4 \pm 1.0$} & $<0.001$ \\
\hline Embryo received, $\mathrm{n}$ & \multicolumn{2}{|c|}{$13.0 \pm 0.7$} & \multicolumn{2}{|c|}{$12.7 \pm 0.6$} & 0.74 \\
\hline Farrowed, \% & \multicolumn{2}{|c|}{$37.5 \pm 8.9$} & \multicolumn{2}{|c|}{$31.8 \pm 7.2$} & 0.62 \\
\hline \multirow[t]{2}{*}{ Litter size, $\mathrm{n}^{4}$} & \multicolumn{2}{|c|}{$7.4 \pm 1.2$} & \multicolumn{2}{|c|}{$8.0 \pm 1.1$} & 0.72 \\
\hline & \multicolumn{2}{|c|}{$2007^{3}(\mathrm{n}=40)$} & \multicolumn{2}{|c|}{$2008(\mathrm{n}=34)$} & \\
\hline Farrowed, \% & \multicolumn{2}{|c|}{$28.0 \pm 7.6$} & \multicolumn{2}{|c|}{$41.3 \pm 8.6$} & 0.26 \\
\hline \multirow[t]{3}{*}{ Litter size, $\mathrm{n}^{4}$} & \multicolumn{2}{|c|}{$8.1 \pm 1.2$} & \multicolumn{2}{|c|}{$7.3 \pm 1.1$} & 0.62 \\
\hline & \multicolumn{2}{|c|}{$-\mathrm{MS}^{2}$} & \multicolumn{2}{|c|}{$-\mathrm{WC} \longrightarrow$} & \\
\hline & $2007^{3}(\mathrm{n}=18)$ & $2008(\mathrm{n}=12)$ & $2007(\mathrm{n}=22)$ & $2008(\mathrm{n}=22)$ & \\
\hline Age, $d$ & $258.9 \pm 1.5^{\mathrm{a}}$ & $189.5 \pm 1.8^{\mathrm{b}}$ & $249.1 \pm 1.4^{\mathrm{c}}$ & $251.8 \pm 1.4^{\mathrm{c}}$ & $<0.001$ \\
\hline \multicolumn{6}{|c|}{$\mathrm{a}^{\mathrm{a}} \mathrm{c}$ Within a row, means without a common superscript differ $(P \leq 0.05)$. } \\
\hline \multicolumn{6}{|c|}{${ }^{1}$ Least squares means \pm SEM. } \\
\hline \multicolumn{6}{|l|}{${ }^{2}$ Recipient breed. } \\
\hline \multicolumn{6}{|l|}{${ }^{3}$ Year. } \\
\hline
\end{tabular}


gilts, and WC piglets were larger $(P \leq 0.01)$ than MS piglets. Analysis of the solution for fixed effects of individual piglet BW illustrated that MUE had a greater effect than PigG, accounting for $64 \%$ of the variation compared with $36 \%$ for PigG. Plasma glucose tended to be increased $(P=0.09)$ in piglets gestated in WC gilts compared with those gestated in MS gilts. In contrast, plasma albumin was increased $(P \leq 0.05)$ in MS piglets compared with WC piglets, irrespective of MUE. There were significant MUE $\times$ PigG interactions for hematocrit and hemoglobin in which MS piglets gestated in WC recipients had the greatest $(P \leq 0.05)$ concentrations of hematocrit and hemoglobin, followed by both breeds of piglets gestated in MS recipients, and the WC piglets gestated in WC recipients had the least concentrations of hematocrit and hemoglobin. A similar tendency $(P=$ 0.06) was observed for PUN concentrations.

\section{Organ Weights, Glycogen Content, and Proximate Analysis}

Table 5 illustrates the organ weights of representative piglets harvested at $\mathrm{d} 1$ of age after intrabreed- and reciprocal-embryo transfer between MS and WC gilts (corrected for BW). Similar to the individual piglet BW, eviscerated BW had both significant MUE and PigG effects in which piglets gestated in WC recipients had increased $(P \leq 0.05)$ eviscerated $\mathrm{BW}$ and WC piglets had increased $(P \leq 0.05)$ eviscerated BW compared with MS piglets. In contrast, total visceral weight was greater $(P \leq 0.01)$ in MS piglets compared with WC piglets, irrespective of MUE. After removal of GI tract contents, no significant difference in emptied visceral weight was observed between the MS and WC piglets. However, the weight of the GI tract content was greater $(P \leq 0.01)$ in the MS piglets compared with WC piglet, again irrespective of MUE. Furthermore, weight of the GI tract alone tended to be greater $(P=0.07)$ in MS piglets compared with WC piglets. There were no significant effects for MUE, PigG, and MUE $\times$ PigG interaction for the weight of the heart, lungs, liver, spleen, or kidneys, although hearts tended to be heavier $(P=0.10)$ in WC piglets compared with MS piglets, and lungs tended to be heavier $(P=0.10)$ in piglets from WC recipients compared with MS recipients.

Table 3. Litter statistics from pregnancies generated by intrabreed- and reciprocal-embryo transfer between Meishan (MS) and White crossbred (WC) gilts ${ }^{1}$

\begin{tabular}{|c|c|c|c|c|c|}
\hline Variable & \multicolumn{2}{|c|}{ Fixed effect } & \multicolumn{2}{|c|}{ Fixed effect } & $P$-value \\
\hline & \multicolumn{2}{|c|}{$\mathrm{MS}^{2}(\mathrm{n}=11)$} & \multicolumn{2}{|c|}{$\mathrm{WC}(\mathrm{n}=14)$} & \\
\hline Farrowed, \% & \multicolumn{2}{|c|}{$51.0 \pm 13.5$} & \multicolumn{2}{|c|}{$38.7 \pm 7.8$} & 0.44 \\
\hline Prenatal survival, \% & \multicolumn{2}{|c|}{$49.4 \pm 8.3$} & \multicolumn{2}{|c|}{$53.2 \pm 6.8$} & 0.73 \\
\hline Perinatal survival, $\%$ & \multicolumn{2}{|c|}{$42.2 \pm 7.6$} & \multicolumn{2}{|c|}{$47.8 \pm 6.2$} & 0.58 \\
\hline Litter size, $\mathrm{n}$ & \multicolumn{2}{|c|}{$6.6 \pm 1.3$} & \multicolumn{2}{|c|}{$7.8 \pm 1.1$} & 0.50 \\
\hline Born alive, $\mathrm{n}$ & \multicolumn{2}{|c|}{$5.5 \pm 1.1$} & \multicolumn{2}{|c|}{$6.8 \pm 1.0$} & 0.39 \\
\hline Gestation length, $d$ & \multicolumn{2}{|c|}{$114.4 \pm 0.5$} & \multicolumn{2}{|c|}{$114.1 \pm 0.4$} & 0.65 \\
\hline \multirow[t]{2}{*}{ Avg. piglet BW, kg } & \multicolumn{2}{|c|}{$1.10 \pm 0.06^{\mathrm{a}}$} & \multicolumn{2}{|c|}{$1.40 \pm 0.05^{\mathrm{b}}$} & 0.003 \\
\hline & \multicolumn{2}{|c|}{$\mathrm{MS}^{3}(\mathrm{n}=11)$} & \multicolumn{2}{|c|}{$\mathrm{WC}(\mathrm{n}=14)$} & \\
\hline Farrowed, \% & \multicolumn{2}{|c|}{$46.3 \pm 13.3$} & \multicolumn{2}{|c|}{$43.4 \pm 8.1$} & 0.86 \\
\hline Prenatal survival, \% & \multicolumn{2}{|c|}{$42.5 \pm 8.5$} & \multicolumn{2}{|c|}{$60.1 \pm 6.5$} & 0.12 \\
\hline Perinatal survival, $\%$ & \multicolumn{2}{|c|}{$41.9 \pm 7.8$} & \multicolumn{2}{|c|}{$48.1 \pm 6.0$} & 0.54 \\
\hline Litter size, $\mathrm{n}$ & \multicolumn{2}{|c|}{$5.8 \pm 1.4$} & \multicolumn{2}{|c|}{$8.7 \pm 1.0$} & 0.11 \\
\hline Born alive, $\mathrm{n}$ & \multicolumn{2}{|c|}{$5.5 \pm 1.1$} & \multicolumn{2}{|c|}{$6.8 \pm 1.0$} & 0.36 \\
\hline Gestation length, d & \multicolumn{2}{|c|}{$112.6 \pm 0.5^{\mathrm{a}}$} & \multicolumn{2}{|c|}{$115.8 \pm 0.4^{\mathrm{b}}$} & $<0.001$ \\
\hline Avg. piglet BW, kg & & & & $05^{\mathrm{b}}$ & 0.02 \\
\hline & $\longrightarrow$ & - & 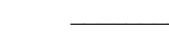 & - & \\
\hline & $\mathrm{MS}^{3}(\mathrm{n}=4)$ & $\mathrm{WC}(\mathrm{n}=7)$ & $\operatorname{MS}(n=7)$ & $\mathrm{WC}(\mathrm{n}=7)$ & \\
\hline Farrowed, \% & $68.8 \pm 25.0^{\mathrm{a}}$ & $33.2 \pm 10.3^{b}$ & $23.8 \pm 9.1^{\mathrm{b}}$ & $53.6 \pm 12.7^{\mathrm{a}}$ & 0.04 \\
\hline Prenatal survival, \% & $36.6 \pm 13.8$ & $62.3 \pm 9.2$ & $48.4 \pm 10.0$ & $60.8 \pm 9.2$ & 0.46 \\
\hline Perinatal survival, $\%$ & $36.6 \pm 12.8$ & $47.8 \pm 8.4$ & $47.3 \pm 9.2$ & $48.4 \pm 8.5$ & 0.61 \\
\hline Litter size, $\mathrm{n}$ & $5.7 \pm 2.2$ & $7.6 \pm 1.5$ & $5.9 \pm 1.6$ & $9.8 \pm 1.5$ & 0.57 \\
\hline Born alive, $\mathrm{n}$ & $5.5 \pm 1.8$ & $5.5 \pm 1.2$ & $5.4 \pm 1.3$ & $8.1 \pm 1.2$ & 0.37 \\
\hline Gestation length, d & $113.1 \pm 0.9$ & $115.7 \pm 0.6$ & $112.2 \pm 0.6$ & $115.9 \pm 0.6$ & 0.41 \\
\hline Avg piglet $\mathrm{BW}, \mathrm{kg}$ & $1.04 \pm 0.11$ & $1.16 \pm 0.07$ & $1.22 \pm 0.08$ & $1.57 \pm 0.07$ & 0.17 \\
\hline
\end{tabular}


Table 6 illustrates the body composition and tissue glycogen concentrations of representative piglets harvested at Day 1 of age after intrabreed- and reciprocal-embryo transfer between MS and WC gilts (corrected for BW). No differences were observed between MUE, PigG, and MUE $\times$ PigG interaction for DM and percentage of ash. In contrast, the percentage of fat, nitrogen, and GE was greater $(P \leq 0.05)$ in MS piglets compared with WC piglets, irrespective of MUE. Interestingly, glycogen concentrations in the liver, bicep femoris, and LM were less $(P \leq$ $0.01)$ in MS piglets compared with WC piglets, irrespective of MUE. In a separate experiment using USMARC pigs, glycogen concentrations in liver, bicep femoris, and LM from MS and WC piglets $(n=9$ per breed from 3 independent naturally bred litters) were not different immediately after parturition (data not shown).

\section{DISCUSSION}

In commercial swine herds, selection for litter size over the past $20 \mathrm{yr}$ has dramatically increased the number of piglets born per litter. However, this increase in litter size has caused a concomitant reduction of piglet birth weights, increased within-litter birth weight variability, and increased pre-weaning piglet mortality. Given that pre-weaning mortality affects $13 \%$ of liveborn piglets in the United States (PigCHAMP, 2010), reducing piglet mortality has a potential to significantly improve sow productivity and thereby increase profits for the swine industry. Although MS piglets weigh significantly less than contemporary Western pig breeds at birth, MS piglets have reduced pre-weaning mortality rates (Legault, 1985; Lee and Haley, 1995). Furthermore,

Table 4. Body weight and blood components of Day 1 piglets resulting from intrabreed- and reciprocal-embryo transfer between Meishan (MS) and White crossbred (WC) gilts ${ }^{1}$

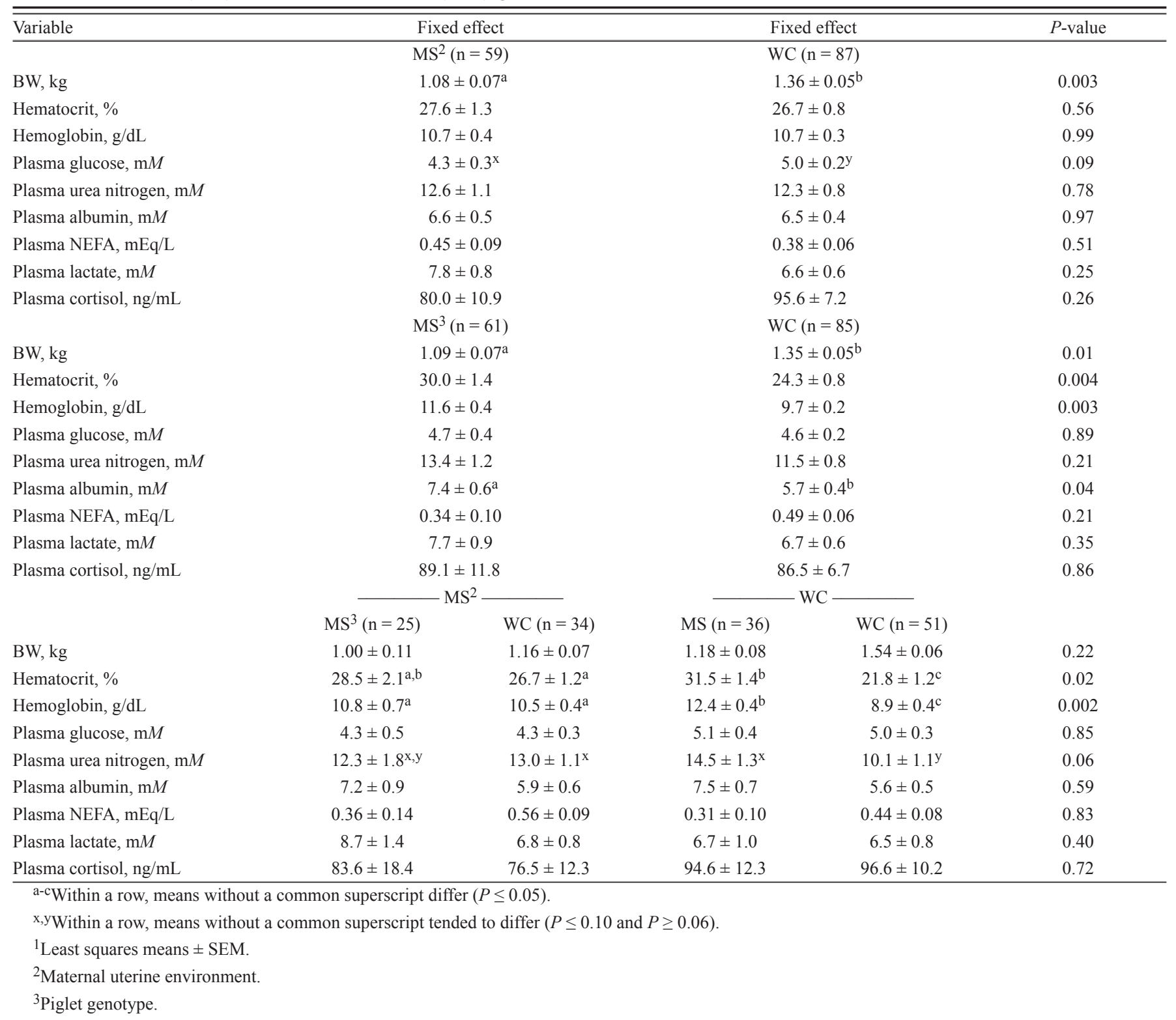


previous studies have suggested that MS piglets have greater physiological maturity immediately after parturition, which likely enhances early neonatal survival (Stone et al., 1985; Le Dividich et al., 1991; Herpin et al., 1993). As a result, the MS pig may serve as a reliable model for studying pre-weaning survivability to identify key developmental pathways that could be targeted to limit pre-weaning piglet mortality in commercial pigs. The current study investigated the contributions of the maternal uterine environment, piglet genotype, and their interaction on the development of neonatal piglets pertaining to pre-weaning survivability by using reciprocal embryo transfers between MS and WC gilts. This study further illustrated that MS piglets, regardless of mater- nal uterine environment, have improved physiological development relating to energy stores, particularly glycogen catabolism, appetite, and oxygen-carrying capacities of the blood that are advantageous to survival of piglets from birth to weaning.

From the embryo recovery results, ovulation rate was greater in MS embryo donors compared with similar-aged WC gilts, but the 2 breeds were similar when MS gilts were approximately $65 \mathrm{~d}$ younger than WC gilts. Meishan gilts typically reach puberty around $100 \mathrm{~d}$ of age (Christenson, 1993; Faillace et al., 1994); whereas typical WC gilts reach puberty around $200 \mathrm{~d}$ of age (Kuehn et al., 2009). As a result, MS gilts similar in age to the WC gilts used in this experiment had a greater

Table 5. Organ weights of Day 1 piglets resulting from intrabreed- and reciprocal-embryo transfer between Meishan (MS) and White crossbred (WC) gilts ${ }^{1}$

\begin{tabular}{|c|c|c|c|c|c|}
\hline Variable & \multicolumn{2}{|c|}{ Fixed effect } & \multicolumn{2}{|c|}{ Fixed effect } & $P$-value \\
\hline & \multicolumn{2}{|c|}{$\mathrm{MS}^{2}(\mathrm{n}=19)$} & \multicolumn{2}{|c|}{$\mathrm{WC}(\mathrm{n}=27)$} & \\
\hline Eviscerated BW, g & \multicolumn{2}{|c|}{$921.0 \pm 10.4^{\mathrm{a}}$} & \multicolumn{2}{|c|}{$948.1 \pm 7.2^{b}$} & 0.05 \\
\hline Total visceral, g & \multicolumn{2}{|c|}{$240.2 \pm 8.9^{\mathrm{x}}$} & \multicolumn{2}{|c|}{$220.8 \pm 6.0^{y}$} & 0.09 \\
\hline Heart, $g$ & \multicolumn{2}{|c|}{$8.4 \pm 0.4$} & \multicolumn{2}{|c|}{$8.5 \pm 0.3$} & 0.81 \\
\hline Lungs, $g$ & \multicolumn{2}{|c|}{$15.3 \pm 0.7^{\mathrm{x}}$} & \multicolumn{2}{|c|}{$16.8 \pm 0.5^{y}$} & 0.10 \\
\hline Liver, $g$ & \multicolumn{2}{|c|}{$28.8 \pm 1.1$} & \multicolumn{2}{|c|}{$29.5 \pm 0.8$} & 0.66 \\
\hline Spleen, $g$ & \multicolumn{2}{|c|}{$1.40 \pm 0.09$} & \multicolumn{2}{|c|}{$1.46 \pm 0.07$} & 0.60 \\
\hline Kidneys, g & \multicolumn{2}{|c|}{$10.8 \pm 0.6$} & \multicolumn{2}{|c|}{$10.7 \pm 0.4$} & 0.88 \\
\hline Gastrointestinal tract, $\mathrm{g}$ & \multicolumn{2}{|c|}{$82.8 \pm 3.7$} & \multicolumn{2}{|c|}{$78.4 \pm 2.8$} & 0.35 \\
\hline Empty visceral, g & \multicolumn{2}{|c|}{$148.0 \pm 4.3$} & \multicolumn{2}{|c|}{$145.2 \pm 3.3$} & 0.60 \\
\hline \multirow[t]{2}{*}{ Gastrointestinal tract content, $\mathrm{g}$} & \multicolumn{2}{|c|}{$93.2 \pm 8.1^{\mathrm{x}}$} & \multicolumn{2}{|c|}{$75.7 \pm 5.5^{y}$} & 0.09 \\
\hline & \multicolumn{2}{|c|}{$\operatorname{MS}^{3}(\mathrm{n}=21)$} & \multicolumn{2}{|c|}{$\mathrm{WC}(\mathrm{n}=25)$} & \\
\hline Eviscerated BW, g & \multicolumn{2}{|c|}{$916.7 \pm 11.2^{\mathrm{a}}$} & \multicolumn{2}{|c|}{$952.3 \pm 7.1^{\mathrm{b}}$} & 0.02 \\
\hline Total visceral, $\mathrm{g}$ & & & & & 0.004 \\
\hline Heart, g & & & & & 0.10 \\
\hline Lungs, $g$ & & & & & 0.49 \\
\hline Liver, $g$ & & & & & 0.81 \\
\hline Spleen, g & & & & & 0.76 \\
\hline Kidneys, g & & & & & 0.89 \\
\hline Gastrointestinal tract, $\mathrm{g}$ & & & & & 0.07 \\
\hline Empty visceral, $\mathrm{g}$ & & & & & 0.21 \\
\hline Gastrointestinal tract content, $\mathrm{g}$ & & & & & 0.007 \\
\hline & $\longrightarrow$ & - & $\longrightarrow$ & - & \\
\hline & $\mathrm{MS}^{3}(\mathrm{n}=8)$ & $\mathrm{WC}(\mathrm{n}=11)$ & MS (n = 13) & $\mathrm{WC}(\mathrm{n}=14)$ & \\
\hline Eviscerated BW, g & $894.1 \pm 17.9$ & $947.8 \pm 10.4$ & $939.3 \pm 11.9$ & $956.9 \pm 10.1$ & 0.17 \\
\hline Total visceral, $\mathrm{g}$ & $267.3 \pm 15.3$ & $213.1 \pm 8.7$ & $232.5 \pm 9.8$ & $209.1 \pm 8.4$ & 0.16 \\
\hline Heart, $g$ & $7.9 \pm 0.6$ & $8.8 \pm 0.4$ & $8.1 \pm 0.4$ & $8.9 \pm 0.4$ & 0.88 \\
\hline Lungs, $g$ & $15.1 \pm 1.2$ & $15.6 \pm 0.7$ & $16.4 \pm 0.7$ & $17.1 \pm 0.6$ & 0.98 \\
\hline Liver, g & $28.9 \pm 1.9$ & $28.8 \pm 1.1$ & $29.0 \pm 1.3$ & $29.9 \pm 1.1$ & 0.71 \\
\hline Spleen, $g$ & $1.39 \pm 0.16$ & $1.42 \pm 0.09$ & $1.44 \pm 0.11$ & $1.49 \pm 0.09$ & 0.98 \\
\hline Kidneys, g & $10.2 \pm 0.9$ & $11.4 \pm 0.5$ & $11.2 \pm 0.6$ & $10.2 \pm 0.5$ & 0.11 \\
\hline Gastrointestinal tract, $\mathrm{g}$ & $87.5 \pm 6.3$ & $78.2 \pm 3.8$ & $83.4 \pm 4.5$ & $73.4 \pm 3.8$ & 0.94 \\
\hline Empty visceral, g & $151.2 \pm 7.3$ & $144.9 \pm 4.5$ & $149.7 \pm 5.3$ & $140.6 \pm 4.5$ & 0.79 \\
\hline Gastrointestinal tract content, $\mathrm{g}$ & $117.3 \pm 13.8$ & $69.1 \pm 7.9$ & $84.2 \pm 9.0$ & $67.2 \pm 7.7$ & 0.13 \\
\hline
\end{tabular}


number of estrous cycles before embryo recovery, and thus greater ovulation rate. This finding supports previous literature illustrating that age-matched ovulation rate of MS gilts are greater than contemporary WC gilts (Ashworth et al., 1990; Christenson, 1993). In contrast, ovulation rates at the first estrus after puberty were not different between the 2 breeds (Christenson, 1993). Although no differences in pregnancy rate (i.e., successful fertilization) were observed between the 2 breeds of embryo donors, total oocyte and subsequently fertilized embryo recovery rate was less in MS donors compared with WC donors. This difference may likely have resulted from reduced integrity of the MS oviduct. The MS oviducts were less rigid and constant compared with the WC oviduct, resulting in greater difficulty in threading flush needles through the infundibulum during embryo recovery and subsequently massaging the oocytes and embryos through the utero-tubal junction. The number of embryos transferred to recipients did not differ by breed, but was greater in 2007 due to the greater ovulation rate of the MS donors in 2007.

After intrabreed- and reciprocal-embryo transfer between MS and WC gilts, overall farrowing rate was reduced in the reciprocal embryo transfer groups compared with the intrabreed embryo transfers. However, there were no differences in pre- and peri-natal survival or litter size and NBA between the embryo transfer groups. These findings suggest that reciprocal embryo transfer groups had greater difficulty establishing pregnancy, but once pregnancy was established, there was no difference in survival. The reduced establishment of pregnancy in reciprocal embryo-transfer groups may be the result of differences in early embryonic development or synchrony between these breeds, which may have occurred because of breed differences in response to the synchronization protocol. A previous reciprocal embryo study investigating embryo survival during early gestation demonstrated that MS embryos from MS donors were less tolerant to routine

Table 6. Tissue glycogen concentrations and body composition of Day 1 piglets resulting from intrabreed- and reciprocal-embryo transfer between Meishan (MS) and White crossbred (WC) gilts ${ }^{1}$

\begin{tabular}{|c|c|c|c|c|c|}
\hline Variable & \multicolumn{2}{|c|}{ Fixed effect } & \multicolumn{2}{|c|}{ Fixed effect } & $P$-value \\
\hline & \multicolumn{2}{|c|}{$\mathrm{MS}^{2}(\mathrm{n}=19)$} & \multicolumn{2}{|c|}{$\mathrm{WC}(\mathrm{n}=27)$} & \\
\hline $\mathrm{DM}, \%$ & \multicolumn{2}{|c|}{$21.5 \pm 0.4$} & \multicolumn{2}{|c|}{$21.2 \pm 0.3$} & 0.54 \\
\hline Fat, \% & \multicolumn{2}{|c|}{$1.8 \pm 0.1$} & \multicolumn{2}{|c|}{$1.7 \pm 0.1$} & 0.38 \\
\hline Ash, $\%$ & \multicolumn{2}{|c|}{$5.1 \pm 0.2$} & \multicolumn{2}{|c|}{$4.8 \pm 0.1$} & 0.35 \\
\hline $\mathrm{GE}, \mathrm{kcal} / \mathrm{g}$ & \multicolumn{2}{|c|}{$4.23 \pm 0.03$} & \multicolumn{2}{|c|}{$4.26 \pm 0.02$} & 0.39 \\
\hline \multirow[t]{2}{*}{ LM glycogen, mg/g } & \multicolumn{2}{|c|}{$57.9 \pm 4.5$} & \multicolumn{2}{|c|}{$57.5 \pm 3.2$} & 0.94 \\
\hline & \multicolumn{2}{|c|}{$\mathrm{MS}^{3}(\mathrm{n}=21)$} & \multicolumn{2}{|c|}{$\mathrm{WC}(\mathrm{n}=25)$} & \\
\hline DM, \% & \multicolumn{2}{|c|}{$21.8 \pm 0.4$} & \multicolumn{2}{|c|}{$21.0 \pm 0.3$} & 0.15 \\
\hline Fat, $\%$ & \multicolumn{2}{|c|}{$2.2 \pm 0.1^{\mathrm{a}}$} & \multicolumn{2}{|c|}{$1.3 \pm 0.1^{b}$} & $<0.001$ \\
\hline $\mathrm{CP}, \%$ & \multicolumn{2}{|c|}{$13.9 \pm 0.5^{\mathrm{a}}$} & \multicolumn{2}{|c|}{$12.8 \pm 0.3^{b}$} & 0.008 \\
\hline LM glycogen, mg/g & & & & & 0.002 \\
\hline & 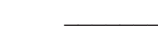 & 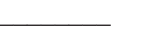 & 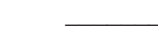 & 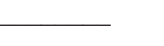 & \\
\hline & $\mathrm{MS}^{3}(\mathrm{n}=8)$ & $\mathrm{WC}(\mathrm{n}=11)$ & $\operatorname{MS}(n=13)$ & $\mathrm{WC}(\mathrm{n}=14)$ & \\
\hline $\mathrm{DM}, \%$ & $21.8 \pm 0.7$ & $21.3 \pm 0.4$ & $21.8 \pm 0.5$ & $20.7 \pm 0.4$ & 0.46 \\
\hline Fat, $\%$ & $2.4 \pm 0.2$ & $1.3 \pm 0.1$ & $2.0 \pm 0.2$ & $1.3 \pm 0.1$ & 0.14 \\
\hline $\mathrm{CP}, \%$ & $13.9 \pm 0.5$ & $12.9 \pm 0.3$ & $14.0 \pm 0.3$ & $12.7 \pm 0.3$ & 0.58 \\
\hline Ash, \% & $5.0 \pm 0.3$ & $5.1 \pm 0.2$ & $4.9 \pm 0.2$ & $4.8 \pm 0.2$ & 0.45 \\
\hline $\mathrm{GE}, \mathrm{kcal} / \mathrm{g}$ & $4.29 \pm 0.06$ & $4.17 \pm 0.03$ & $4.30 \pm 0.04$ & $4.23 \pm 0.03$ & 0.56 \\
\hline Liver glycogen, mg/g & $8.7 \pm 4.5$ & $30.0 \pm 8.5$ & $9.0 \pm 2.9$ & $36.0 \pm 9.8$ & 0.83 \\
\hline B. femoris glycogen, $\mathrm{mg} / \mathrm{g}$ & $32.4 \pm 5.8$ & $46.2 \pm 5.0$ & $27.6 \pm 3.5$ & $46.4 \pm 4.9$ & 0.52 \\
\hline
\end{tabular}


embryo transfer compared with WC embryos from WC donors, as indicated by the percentage of viable embryos at Day 30 of gestation (Ashworth et al., 1990). However, once pregnancy was established, there were no statistical differences in pre- and peri-natal survival, litter size, or NBA in embryo transfer groups at term in the current study. It is important to note that MS piglets, irrespective of MUE, had numerically decreased litter size and prenatal survival, which further suggests that MS embryos may be less tolerant to routine embryo transfer, as was observed by Ashworth et al. (1990). In contrast to early embryonic loss, results of a previous reciprocal embryo transfer study in which litter size was measured during late gestation indicated that litter size and conceptus viability did not differ between reciprocal embryo transfer groups from MS and Yorkshire gilts (Biensen et al., 1998; Wilson et al., 1998). The differences among embryo survival during early gestation (Ashworth et al., 1990), late gestation (Biensen et al., 1998; Wilson et al., 1998), and term (lack of statistical differences in the current study) may reflect differences in the timing of embryonic loss after embryo transfer and suggest that embryos for either breed or uterine environment have similar sensitivity to fetal loss during late gestation and at term after embryo transfer. Gestation length was greater in WC piglets compared with MS piglets, regardless of MUE, and illustrated that PigG plays a key role in initiating parturition. These gestation lengths are consistent with naturally bred MS (Canario et al., 2009) and commercial WC breeds (Straw et al., 2008).

Piglet BW, both litter-average and individual-piglet basis, was greater in piglets gestated in WC gilts, irrespective of PigG, demonstrating an advantage in pre- and peri-natal growth in WC gilts. This finding supports crossbreeding studies between MS and LW pigs demonstrating that birth weight was attributed to a significant maternal effect in favor of the LW dam (Bidanel et al., 1990; Lee and Haley, 1995). In a reciprocal transfer study between MS and Yorkshire pigs, Wilson et al. (1998) demonstrated a fetal breed $\times$ recipient breed interaction for fetal weight at Day 90 of gestation, in which fetuses gestated in MS recipients were lighter than fetuses gestated in Yorkshire recipients. In contrast, MS fetuses gestated in Yorkshire recipients were lighter than Yorkshire fetuses gestated in Yorkshire recipients at Day 90 of gestation; however, by term there was no difference observed in the BW of MS piglets or Yorkshire piglets gestated in Yorkshire gilts. The authors concluded that the MS uterine environment resulted in a suppressive effect on the growth of fetuses, irrespective of fetal breed. This pattern was also observed in the current study at term, further suggesting a suppressive effect of the MS uterine environment on Day-1 piglet $\mathrm{BW}$, irrespective of PigG. Interestingly, piglet BW, again on both a litter-average and individual-piglet basis, was not only greater for piglets gestated in WC gilts, but WC piglets were heavier than MS piglets. The current findings indicate that the MS uterine environment has a propensity to reduce piglet size, but the WC piglet has attributes that were able to partially circumvent this suppression. This somewhat contradicts the previous reciprocal embryo transfer study by Wilson et al. (1998), suggesting that the suppressive effect of the MS uterine environment on fetal growth of WC piglets may not be as dramatic when comparing a composite White breed as when comparing a purebred Yorkshire breed. Furthermore, the previous study co-transferred MS and Yorkshire embryos within the same litter, which may have resulted in interactions between the fetal genotypes within individual litters and reduced differences in fetal weights. However, it is important to highlight that the MUE affected piglet BW, both on a litteraverage and individual-piglet basis, greater than PigG in the current study, thereby still supporting the previous observation of a suppressive effect on prenatal growth by the MS uterine environment (Wilson et al., 1998).

Plasma albumin concentrations were increased in MS piglets compared with WC piglets at Day 1 of life, irrespective of MUE. This is consistent with the previous pattern of increased albumin in MS piglets compared with composite-line piglets at birth (Herpin et al., 1993), suggesting that MS piglets, despite their decreased size, have greater maturation of the liver (Herpin et al., 1993) because albumin concentrations are indicative of the physiological maturity of the liver (Stone, 1984). Hematocrit and hemoglobin concentrations were elevated in MS piglets compared with WC piglets gestated in WC gilts. This finding is consistent with the finding of Herpin et al. (1993) that illustrated increased hematocrit concentrations immediately after birth in MS piglets compared with LW and composite line piglets. Furthermore, WC piglets gestated in MS gilts had greater concentrations of hematocrit and hemoglobin compared with intrabreed WC piglets. Hemoglobin is a protein produced by red blood cells that delivers oxygen to the tissues, and hematocrit corresponds to the volume of red blood cells in the total blood volume (Billett, 1990). As a result, hematocrit and hemoglobin concentrations are highly correlated in the pig (Miller et al., 1961). Increased hematocrit and hemoglobin concentrations in the current study demonstrated that erythrocytes from MS piglets have improved oxygen-carrying capacity, and the MS uterine environment appeared to improve the oxygen-carrying capacity compared with the WC uterine environment, which likely benefits early neonatal survival. Furthermore, lower hematocrit and hemoglobin concentrations in intrabreed WC may reflect greater deficiency in iron, a correlative factor with hematocrit and hemoglobin concentrations (Miller et al., 1961). Interestingly, a similar tendency was observed for PUN concentrations. This may reflect 
differences in kidney function given that the kidney regulates erythropoiesis in neonatal pigs via production of erythropoietin (David et al., 2002). Alternatively, in creased PUN in MS piglets and piglets gestated in MS gilts may reflect differences in the efficiency of AA use. Given these differences in oxygen-carrying capacities and possible kidney function, further experimentation investigating erythropoiesis and hemoglobin production during prenatal and neonatal development between MS and WC piglets has the potential to identify unique targets for improving pre-weaning survival of piglets.

In a representative group of piglets harvested at Day 1 of life from each litter, eviscerated BW followed a similar pattern observed for the litter average and individual piglet BW in which both MUE and PigG affected piglet BW in favor of the WC breed. However, total visceral weight had an opposite effect in which MS piglets had increased visceral weight compared with WC piglets, irrespective of MUE. There was a lack of significant effects on organ weights and empty visceral weight between the breeds. Interestingly, GI tract content weight was greater in MS piglets, irrespective of MUE. This illustrated that MS piglets had greater colostrum intake on the first day of life, which could improve piglet survivability. Literature comparing colostrum and milk intake of piglets during early neonatal life in MS and contemporary breeds is lacking. However, several studies have investigated activity of sows and piglets from MS and contemporary Western breeds immediately after parturition (Meunier-Salaun et al., 1991) and during lactation (Sinclair et al., 1998; Farmer et al., 2001). During the first $24 \mathrm{~h}$ postpartum, Meunier-Salaun et al. (1991) reported that MS and LW sows spent $>90 \%$ of the time lying down with no breed effects for sow activity. In contrast, MS piglets spent a greater amount of time at the udder (74\%) compared with WC piglets (54\%), which allowed MS piglets more heat and nutritional energy from the sows (Meunier-Salaun et al., 1991). This would further support the current observation of greater colostrum intake by MS piglets during the first day of life. Follow-up studies monitoring intake and appetite between MS and contemporary Western piglets would be useful for identifying potential methods to increase intake of commercial piglets during the first days of life to improve pre-weaning survivability.

In the current study, MS piglets had greater fat and protein contents than WC piglets, irrespective of MUE. This illustrates greater energy stores in the carcass of an MS piglet at Day 1 of life, which could be beneficial to piglet survival. This supports previous literature that demonstrated MS piglets have greater fat and protein contents immediately after parturition compared with composite-line piglets (Herpin et al., 1993). Le Dividich et al. (1991) also showed increased protein contents in MS piglets compared with LW piglets immediately after parturition, but did not find differences in fat contents between MS and LW piglets. Differences between Le Dividich and others and the current study likely occurred due to difference in contemporary White pig genetics (i.e., a European, purebred LW breed versus in the current study a composite line selected for leaner growth).

At d 1 of life, glycogen concentrations were greater in liver, bicep femoris, and LM from WC piglets compared with MS piglets, irrespective of MUE. However, no differences in liver, bicep femoris, and LM glycogen concentrations were observed immediately after birth of MS and WC piglets from naturally bred pigs at the USMARC (Miles, unpublished observation). Similar liver and muscle glycogen concentration patterns were also observed in MS and LW piglets immediately after parturition (Le Dividich et al., 1991). These findings demonstrate greater catabolism of glycogen on the first day of life in MS piglets compared with WC piglets, which could be advantageous to piglet survival given that glycogen is a key energy source in the neonatal piglet (van der Lende et al., 2001). From observations over the past $25 \mathrm{yr}$ of the USMARC MS population, MS piglets are more active during the first few days of life compared with WC piglets; however, MS piglet activity steadily declines after $\sim 1 \mathrm{wk}$ to be similar or even less than that of WC piglets. Similar activity has also been observed in other crossbred MS populations during lactation (Sinclair et al., 1998; Farmer et al., 2001). Increased physical activity enhances glycogen metabolism, particularly in the muscles (Sakamoto and Goodyear, 2002). It is unknown whether increased activity in MS piglets during the first day of life increases glycogen catabolism in MS piglets or whether an intrinsic increase in glycogen catabolism in MS piglets leads to increased activity on the first day of life. Studies using the MS breed are ongoing to better understand activity during early life and glycogen metabolism during prenatal and early neonatal development and how glycogen metabolism benefits pre-weaning piglet survivability.

In conclusion, the results of this study indicate that the MS breed serves as a suitable model for studying pre-weaning survivability. This study demonstrates that MS piglets, regardless of uterine environment, have improved physiological development that enhances their early neonatal survivability. As a result, use of the MS piglet to study components relating to oxygen-carrying capacities of the blood, appetite, activity, and energy stores, particularly glycogen, has the potential to identify specific factors associated with piglet survival. Identified factors associated with piglet survival can then serve as possible targets to limit pre-weaning mortality in commercial pigs. 


\section{LITERATURE CITED}

AOAC. 1997. Official Methods of Analysis. 15th ed. Assoc. Off. Anal. Chem., Gaithersburg, MD.

Ashworth, C. J., C. S. Haley, R. P. Aitken, and I. Wilmut. 1990. Embryo survival and conceptus growth after reciprocal embryo transfer between Chinese Meishan and Landrace $\times$ Large White gilts. J. Reprod. Fertil. 90:595-603.

Bidanel, J. P., J. C. Caritez, and C. Legault. 1990. Estimation of crossbreeding parameters between Large White and Meishan porcine breeds. II. Growth before weaning and growth of females during the growing and reproductive periods. Genet. Sel. Evol. 22:431-445.

Biensen, N. J., M. E. Wilson, and S. P. Ford. 1998. The impact of either a Meishan or Yorkshire uterus on Meishan or Yorkshire fetal and placental development to days 70, 90, and 110 of gestation. J. Anim. Sci. 76:2169-2176.

Billett, H. H. 1990. Hemoglobin and hematocrit. Pages 718-719 in Clinical Methods: The History, Physical, and Laboratory Examinations. H. K. Walker, W. D. Hall, and J. W. Hurst, ed. Butterworths, Boston, MA.

Canario, L., Y. Billon, J. C. Caritez, J. P. Bidanel, and D. Laloë. 2009. Comparison of sow farrowing characteristics between a Chinese breed and three French breeds. Livest. Sci. 125:132-140.

Carroll, N. V., R. W. Longley, and J. H. Roe. 1956. The determination of glycogen in liver and muscle by use of anthrone reagent. J. Biol. Chem. 220:583-593.

Christenson, R. K. 1993. Ovulation rate and embryonic survival in Chinese Meishan and white crossbred pigs. J. Anim. Sci. 71:3060-3066.

Damgaard, L. H., L. Rydhmer, P. Løvendahl, and K. Grandinson. 2003. Genetic parameters for within-litter variation in piglet birth weight and change in within-litter variation during suckling. J. Anim. Sci. 81:604-610.

David, R. B., A. K. Blom, I. Harbitz, T. Framstad, and Ø. V. Sjaastad. 2002. Responses of plasma Epo and kidney and liver Epo mRNA to hemorrhage in perinatal pigs. Domest. Anim. Endocrinol. 23:507-516.

Faillace, L. S., C. Biggs, and M. G. Hunter. 1994. Factors affecting the age at onset of puberty, ovulation rate and time of ovulation in Chinese Meishan gilts. J. Reprod. Fertil. 100:353-357.

Farmer, C., M. F. Palin, M. T. Sorensen, and S. Robert. 2001. Lactational performance, nursing and maternal behavior of Upton-Meishan and Large White sows. Can. J. Anim. Sci. 81:487-493.

Haley, C. S., G. J. Lee, and M. Ritchie. 1995. Comparative reproductive performance in Meishan and Large White pigs and their crosses. Anim. Sci. 60:259-267.

Herpin, P., J. Le Dividich, and N. Amaral. 1993. Effect of selection for lean tissue growth on body composition and physiological state of the pig at birth. J. Anim. Sci. 71:2645-2653.

Holl, J. W., G. A. Rohrer, S. D. Shackelford, T. L. Wheeler, and M. Koohmaraie. 2008. Estimates of genetic parameters for kyphosis in two crossbred swine populations. J. Anim. Sci. 86:1765-1769.

Kuehn, L. A., D. J. Nonneman, J. M. Klindt, and T. H. Wise. 2009. Genetic relationships of body composition, serum leptin, and age at puberty in gilts. J. Anim. Sci. 87:477-483.

Le Dividich, J., P. Mormède, M. Catheline, and J. C. Caritez. 1991. Body composition and cold resistance of the neonatal pig from European (Large White) and Chinese (Meishan) breeds. Biol. Neonate 59:268-277.
Lee, G., and C. Haley. 1995. Comparative farrowing to weaning performance in Meishan and Large White pigs and their crosses. Anim. Sci. 60:269-280.

Legault, C. 1985. Selection of breeds, strains and individual pigs for prolificacy. J. Reprod. Fertil. Suppl. 33:151-166.

Meunier-Salaün, M. C., F. Gort, A. Prunier, and W. P. G. Schouten. 1991. Behavioural patterns and progesterone, cortisol and prolactin levels around parturition in European (Large-White) and Chinese (Meishan) sows. Appl. Anim. Behav. Sci. 31:43-59.

Miller, E. R., D. E. Ullrey, I. Ackermann, D. A. Schmidt, R. W. Luecke, and J. A. Hoefer. 1961. Swine hematology from birth to maturity. II. Erythrocyte population, size and hemoglobin concentration. J. Anim. Sci. 20:890-897.

NRC. 1998. Nutrient Requirements of Swine. 10th rev. ed. Natl. Acad. Press, Washington, DC.

PigCHAMP. 2010. USA 2010-Annual Summary. Verified 22 May 2012. http://www.pigchamp.com/LinkClick.aspx?fileticket=gQ VNiO0HvjA\%3d\&tabid=237.

Sakamoto, K. and L. J. Goodyear. 2002. Invited Review: Intracellular signaling in contracting skeletal muscle. J. Appl. Physiol. 93:369-383.

Sinclair, A. G., S. A. Edwards, S. Hoste, and A. McCartney. 1998. Evaluation of the influence of maternal and piglet breed differences on behaviour and production of Meishan synthetic and European White breeds during lactation. Anim. Sci. 66:423-430.

Steel, R. G. D., J. H. Torrie, and D. A. Dickey. 1997. Principles and Procedures of Statistics: A Biometrical Approach. 3rd ed. McGraw-Hill., New York.

Stone, R. T. 1984. Relationship of alpha-fetoprotein and albumin in fetuses and neonates from genetically lean and obese swine. Biol. Neonate 46:122-130.

Stone, R. T., D. R. Campion, J. Klindt, and R. J. Martin. 1985. Blood parameters and body composition in fetuses from reciprocal crosses of genetically lean and obese swine. Proc. Soc. Exp. Biol. Med. 180:191-195.

Straw, B., R. Bates, and G. May. 2008. Influence of method of administration of prostaglandin on farrowing and relationship between gestation length and piglet performance. J. Swine Health Prod. 16:138-143.

Tuchscherer, M., B. Puppe, A. Tuchscherer, and U. Tiemann. 2000. Early identification of neonates at risk: Traits of newborn piglets with respect to survival. Theriogenology 54:371-388.

van der Lende, T., E. F. Knol, and J. I. Leenhouwers. 2001. Prenatal development as a predisposing factor for perinatal losses in pigs. Reprod. Suppl. 58:247-261.

Wilson, M. E., N. J. Biensen, C. R. Youngs, and S. P. Ford. 1998. Development of Meishan and Yorkshire littermate conceptuses in either a Meishan or Yorkshire uterine environment to day 90 of gestation and to term. Biol. Reprod. 58:905-910.

Wise, T., E. L. Zanella, D. D. Lunstra, and J. J. Ford. 2000. Relationships of gonadotropins, testosterone, and cortisol in response to $\mathrm{GnRH}$ and $\mathrm{GnRH}$ antagonist in boars selected for high and low follicle-stimulating hormone levels. J. Anim. Sci. 78:1577-1590.

Youngs, C. R., L. K. Christenson, and S. P. Ford. 1994. Investigations into the control of litter size in swine: III. A reciprocal embryo transfer study of early conceptus development. J. Anim. Sci. 72:725-731. 